

\title{
Hybrid systems energy management using optimization method based on dynamic sources models
}

Yacine Gaoua, Stéphane Caux, Pierre Lopez, C Raga, A Barrado, A Lázaro

\section{To cite this version:}

Yacine Gaoua, Stéphane Caux, Pierre Lopez, C Raga, A Barrado, et al.. Hybrid systems energy management using optimization method based on dynamic sources models. IEEE Vehicle Power and Propulsion Conference (VPPC 2014), Oct 2014, Coimbra, Portugal. 9p. hal-01104099

\section{HAL Id: hal-01104099 \\ https://hal.science/hal-01104099}

Submitted on 16 Jan 2015

HAL is a multi-disciplinary open access archive for the deposit and dissemination of scientific research documents, whether they are published or not. The documents may come from teaching and research institutions in France or abroad, or from public or private research centers.
L'archive ouverte pluridisciplinaire $\mathbf{H A L}$, est destinée au dépôt et à la diffusion de documents scientifiques de niveau recherche, publiés ou non, émanant des établissements d'enseignement et de recherche français ou étrangers, des laboratoires publics ou privés. 


\title{
Hybrid systems energy management using optimization method based on dynamic sources models
}

\author{
Y. Gaoua, S. Caux, P. Lopez* \\ Toulouse University - France \\ Laplace UMR5213 INPT/UPS/CNRS - 2 rue Camichel \\ 31071 Toulouse Cedex 7 \\ * LAAS/CNRS avenue du colonel Roche, 31500 Toulouse \\ gaoua@laplace.univ-tlse.fr, caux@laplace.univ-tlse.fr, \\ lopez@laas.fr
}

\author{
C. Raga, A. Barrado, A. Lázaro \\ Universidad Carlos III de Madrid - SPAIN \\ Avda. de la Universidad 30, \\ 28911, Leganés, Madrid \\ mraga@ing.uc3m.es, barrado@ing.uc3m.es, \\ alazaro@ing.uc3m.es
}

\begin{abstract}
This paper focus on offline energy management strategy based on dynamic losses computation made on accurate sources models. Hybrid energy systems (mainly Hybrid Electric Vehicle) should now be managed globally to reach the optimal operation minimizing a global cost criterion, such as hydrogen consumption. The presented operational research method is applied to a Fuel Cell based Vehicle (FCV) powertrain, and it has been adapted to the mathematical model depending on the sources characteristics (fuel cell and battery). In this paper losses and efficiency curves are issued from an accurate nonlinear model using experiments for both sources providing data representing the sources behavior to feed the optimization algorithm. Consumption comparisons on actual mission profiles demonstrate the optimal power splitting obtained.
\end{abstract}

Keywords- Hybrid systems, Energy source model, Linear optimization, Global optimization, Fuel cell modelling, Fuel cell based vehicles

\section{INTRODUCTION}

Due to world economic evolution driven by fossil oil market, there is an increasing interest developing hybrid systems. Mainly in transport application, it is now well known full Hybrid Electrical Vehicle should be a solution to fossil oil crisis and NOx emission reduction [1-2]. In such HEV almost two energy sources are used, a main source made of a Fuel Cell Stack is used in this research paper associated to a reversible battery source (stores and delivers energy). Autonomy is also increased when consumption is minimized on a given mission. To do so, an accurate behavior of both sources should be determined and an optimization procedure should be implemented to optimally split the power demand between the two sources [3-5].

Depending on the nonlinear behavior of the energy sources a first step should be made in sources modeling and design. The models used for optimization loops should be as accurate as possible and not only based on static data provided by manufacturer in datasheets because the sources are solicited dynamically during an effective mission [6].

Considering the sources known and the mission power demand registered with a given step time from the beginning to the end, offline optimization method can be run. In fact the proposed method uses mathematical modeling of the optimization problem and presents an algorithm adapted from Operational Research field. The input data request at instant $t k$ is provided by the models of sources running from $t k-1$ to $t k$. The cost function and constraints to respect are included in the mathematical problem and different objectives are proposed:

$\mathrm{Pb} 1$ : Minimize the total energy losses in the system (global efficiency) while respecting all the different constraints of system operating points.

$\mathrm{Pb}$ 2: Minimize the total power provided by the FC (main source consumption) while respecting all the different constraints of the system operating points.

The paper is organized as follows: Part II presents the nonlinear electrical equivalent models of the battery and the fuel cell source. R, C elements present different values, due to various operating point used during the mission (power to be delivered), identification is based on various experiments allowing thus computing accurate losses for optimization purposes. Part III presents the mathematical formulation of the optimization problems ( $\mathrm{Pb} 1$ and $\mathrm{pb} 2)$ using previous losses computed data. Part III presents results obtained with actual data of a Fuel Cell based Vehicle. Conclusions and perspectives are given at the end.

\section{PROPULSION SYSTEM AND ENERGY SOURCES MODELLING}

\section{A. Powertrain chain}

The powertrain analyzed, Fig. 1, shows the fuel cell as main energy source and a battery as secondary energy source, connected in parallel to the de voltage bus. All the power and energy that the fuel cell is not able to provide will be delivered by the battery. In braking phase, energy recovery is stored in battery (no fuel cell reversibility). 


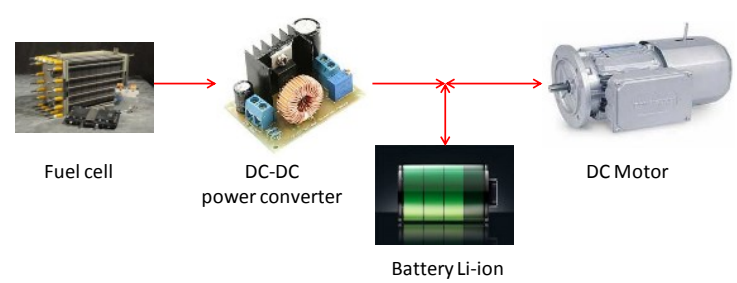

Fig. 1. Propulsion system block diagram

The nominal power of the fuel cell is $1.2 \mathrm{~kW}$, and the secondary source is a Lithium-ion battery characterized by its nominal voltage $V$ nom $=72 \mathrm{~V}$ and its capacity $Q \max =4.549 \mathrm{Ah}$. The optimal sizing of the powertrain energy systems is thoroughly described in [7].

\section{B. Powertrain losses chain}

In order to deal with the mathematical formulation, the following block diagram of Fig. 2 is considered.

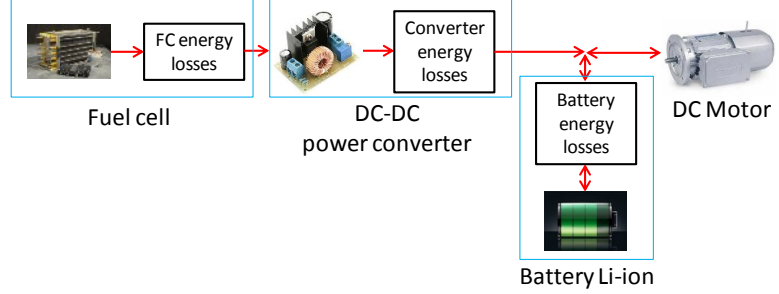

Fig. 2. Electrical elements and their losses in the powertrain losses chain

According to the structure presented Fig. 1, a battery model and a fuel cell model are established. The modeling is oriented to well compute current and voltage behavior allowing computing instantaneous losses (at $t k$ ) in equivalent resistance whatever the battery or fuel cell operating points.

The moto-propulsion group is resumed in power demand on the DC-bus (positive power for traction, negative in braking phase, zero at stop).

\section{Battery modeling}

Several works have been conducted in order to deduce the battery voltage behavior according to its operation mode: charge or discharge mode. The model used is the provided one by MATLAB ${ }^{\mathrm{TM}}$, and the voltage equation is defined by (1):

$$
V_{B}=V_{o c}-R \cdot I_{b a t}-K \cdot i t .\left(\frac{Q_{\max }}{Q_{\max }-i t}\right)+A e^{-B . i t}
$$

Where $V_{o c}$ is battery constant voltage $(\mathrm{V}), K$ is the polarization constant (V/Ah), $A$ is magnitude in exponential zone (V), $B$ is the inverse time constant $\left(\mathrm{Ah}^{-1}\right), i t=\int i_{\text {bat }} d t$ the instantaneous battery charge $(\mathrm{Ah})$. Doing so, an equivalent nonlinear electrical model presented Fig. 3 is derived. The battery voltage depends on its capacity and the current passes through its internal resistance $R v$.

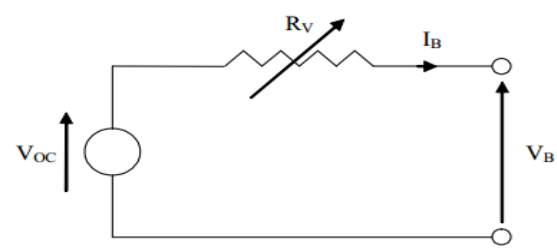

Fig. 3. Electrical model of battery source

$V_{o c}, K, A, B$ are determined (identification are presented in [8]), using PowerSim Matlab ${ }^{\mathrm{TM}}$ toolbox, not only with data sheets, but also with several operating points coming from manufacturers and measurements and analyzed with Fig. 4.

In order to use the battery voltage equation in an optimization mathematical model, polynomial approximation is necessary to transform the nonlinear equation into polynomial equation reducing the computational complexity of the energy management algorithm and not losing accuracy. 


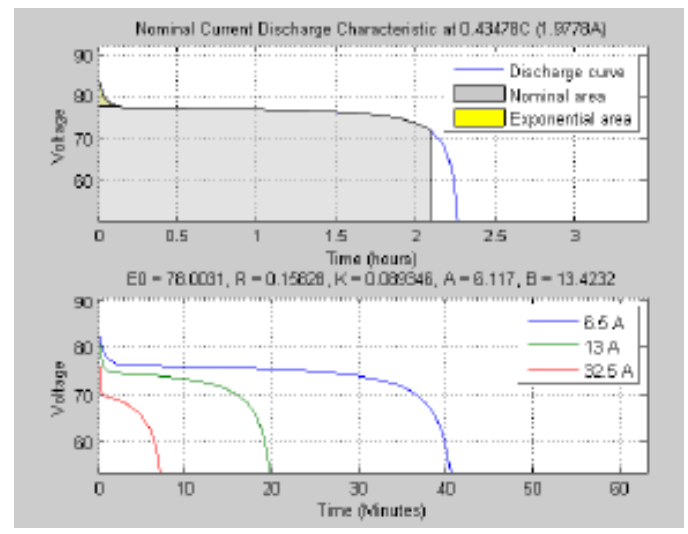

Fig. 4. Simulation based parameters identification

Simulations, using the static battery model from MATLAB, were performed by fixing the discharge (resp. charge) current to 1A (resp. -1A), with the aim of measuring both the battery open circuit voltage $V_{o c}$ and the State Of Charge (SOC). After that, the battery open circuit as a function of the $\mathrm{SOC}$ is obtained $(\mathrm{K}=0.099, \mathrm{~A}=8.11, \mathrm{~B}=13.42)$, as Fig. 5 depicts.

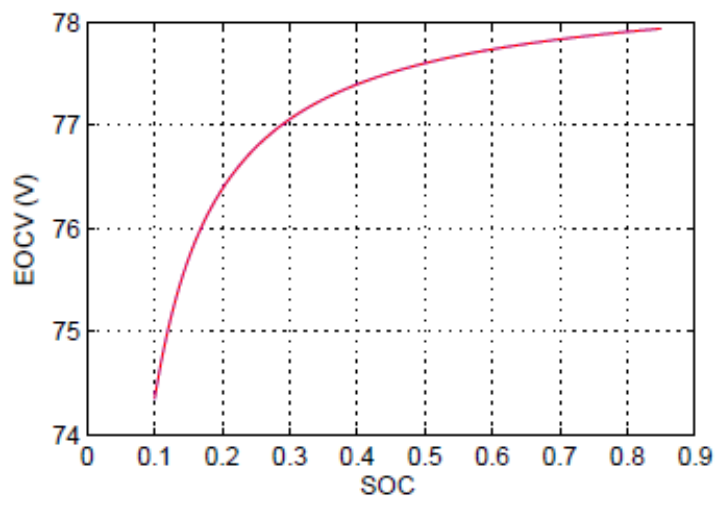

Fig. 5. Battery behavior approximated curve

Where :

$E_{\text {bat }}=V_{o c}-K$. it. $\left(\frac{Q_{\max }}{Q_{\max }-i t}\right)+A e^{-B . i t}$, can be also written using battery SOC after polynomial approximation (degree $n=$ $10)$.

$$
\begin{aligned}
& \text { Ebat }_{o c v}=\sum_{i=0}^{n} b_{i} \cdot S O C^{n-i} \\
& V_{B}=E_{b a t}-R . I_{\text {ocv }}-R
\end{aligned}
$$

\section{D. $\quad$ Fuel Cell modelling}

The main source in the propulsion system is a fuel cell, which produces energy via the chemical reaction of hydrogen and oxygen. The advantages of using fuel cell in electric vehicles derive from its high efficiency that exceeds $40 \%$, the generation of electrical energy with little fuel consumption and no NOx emission, unlike the performance of Internal Combustion Engine which varies between $25 \%$ and $30 \%$ emitting pollutant.

There are two possible voltage transient responses when a load current step is applied to a fuel cell: overdamped and overshooted [9], and several fuel cell models reproducing both kind of behaviors can be found in the literature [10]-[11].

A commercial Nexa Ballard 1.2kW PEM fuel cell, with overshooted transient response has been modeled, by means of the identification methodology described in [12]. This procedure is based on manufacturer's datasheets and simple measurements in the time domain.

The PEM fuel cell model is shown in Fig. 6, where $E_{o c}$ is the open circuit voltage, resistors $R_{s}$ and $R_{v}\left(i_{f c}\right)$ model the static I-V curve, and the capacitor $C_{p}$, the inductor $L$ and the resistor $R_{L}\left(i_{f c}\right)$ model the dynamic behavior of the fuel cell. The diode assures the unidirectional fuel cell operation. 


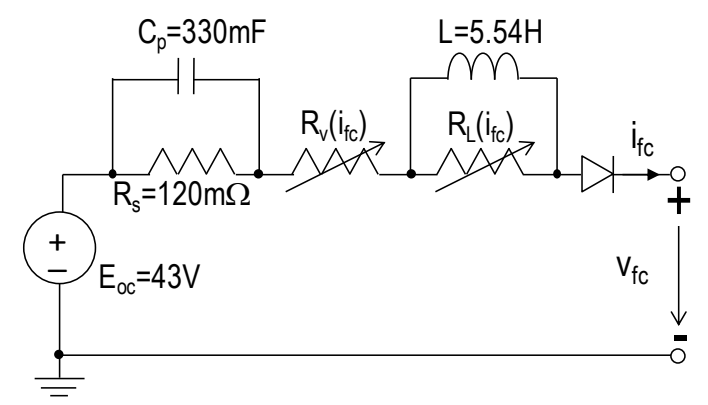

Fig. 6. Nexa Ballard 1.2kW PEM fuel cell model.

The resistors $R_{s}$ and $R_{v}\left(i_{f c}\right)$ values are calculated from the quasi-static I-V curve, which can be provided by the manufacturers or by means of simple measurements on the fuel cell. The value of the resistor is constant $R s=120 \mathrm{~m} \Omega$, and is calculated from the fuel cell output voltage considering only the ohmic region. Due to this fact, the resistor $R_{v}\left(i_{f c}\right)$ gets variable values depending on the fuel cell current $i_{f c}$. Table I shows the collected data presenting the variation.

\begin{tabular}{c|c||c|c}
\multicolumn{4}{c}{ TABLE I. StATIC FUEL CELL MODEL PARAMETERS } \\
\hline \hline$i_{f c}(\mathrm{~A})$ & $R_{v}\left(\mathrm{i}_{\mathrm{fc}}\right)(\Omega)$ & $i_{f c}(\mathrm{~A})$ & $R_{v}\left(\mathrm{i}_{\mathrm{fc}}\right)(\Omega)$ \\
\hline 1 & 1.780 & 25 & 0.312 \\
\hline 2 & 1.080 & 30 & 0.279 \\
\hline 3 & 1.013 & 35 & 0.251 \\
\hline 4 & 0.905 & 40 & 0.229 \\
\hline 5 & 0.820 & 42 & 0.225 \\
\hline 8 & 0.630 & 43 & 0.222 \\
\hline 10 & 0.550 & 44 & 0.221 \\
\hline 15 & 0.427 & 45 & 0.227 \\
\hline 20 & 0.358 & & \\
\hline \hline
\end{tabular}

The fuel cell quasi-static model, parameterized following [12], is shown in Fig. 7, where $E_{o c}=43 \mathrm{~V}$.

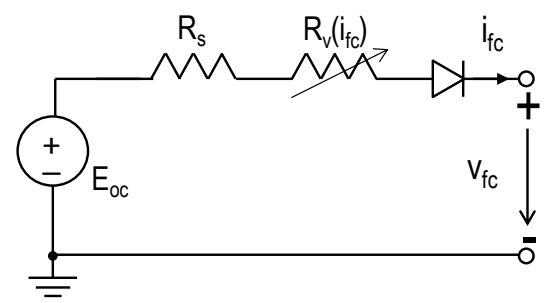

Fig. 7. Static model of the PEM fuel cell.

And finally, the behavior of the fuel cell model is shown together the experimental response in Fig. 8.



Fig. 8. Comparison between measured fuel cell I-V curve and simulated fuel cell model I-V curve. 
In order to reproduce the quasi-static FC behavior and run the mathematical simulations, the FC voltage equation given in (3) can be written.

$$
V_{f c}=E_{o c}-R_{s} i_{f c}-R_{v}\left(i_{f c}\right) i_{f c}
$$

With the aim of using this model in the optimization step, the FC voltage behavior is computed with polynomial approximation (degree $n=15$ ) to identify the $R_{v}$ equation (4). Allowing now, running simulations with the electrical equivalent model shown in Fig 7.

$$
R_{v}\left(i_{f c}\right)=\sum_{i=0}^{n} a_{i} \cdot i_{f c}{ }^{n-i}
$$

To be noticed: the FC is connected to the DC bus through power electronic converter device. The battery is directly linked to this DC bus. Thus the power demand (indexed busload) is the sum of battery power and FC power on bus side (indexed bus to indicate exit of FC stack after the converter). Knowing that the efficiency of the boost converter is $\eta$ generally $[0.95 ; 1](5)$ is used.

$P_{\text {busload }}=P_{B}+P_{\text {bus }}$ (power splitting) will be managed when the vehicle is in traction or when the vehicle brakes.

$$
P_{b u s}(t)=P_{f c}(t) \mathrm{n} \text { and } P_{b u s}(t)=I_{b u s}(t) V_{B}(t)
$$

The losses and exact computation of all electrical values allows feeding the hereafter presented optimization algorithm with effective input data. The objective of the optimization is now to split the power demand dealing with a compromise using fuel cell or battery to minimize a criterion.

These models (battery and fuel cell), can also be used in PSIM or Matlab/Simulink, or HIL environment to dynamically compute the current, the voltage and thus losses in both elements, when references are given to deliver the power demand (every $1 \mathrm{~s}$ in our case) running from the beginning to the end of the mission.

\section{E. Driving profile}

The energy and power required by the load (dc motor and vehicle), depends the applied driving cycle [13]-[14]. This analysis is focused on a light vehicle of $800 \mathrm{~kg}$, propelled by a motor drive of nominal power $4.7 \mathrm{~kW}$ which is able to provide a peak power of $18 \mathrm{~kW}$. An European urban driving cycle is applied, ECE-15, which maximum speed of $50 \mathrm{~km} / \mathrm{h}$ and the total time is $181 \mathrm{~s}$. Fig. 9 shows the load power requirement that derive from the driving cycle and the vehicle features. In order to evaluate the fuel consumption during a working day of $8 \mathrm{~h}$, the aforementioned driving cycle will be applied 161 times.

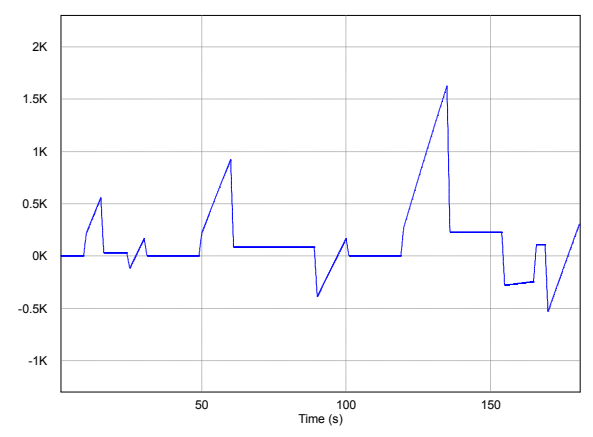

Fig. 9. Load power $(\mathrm{kW})$ requirement.

\section{OPTIMIZATION FORMULATION}

\section{A. Mathematical Formulation}

The goal of this study is managing the energy distribution of the system in order to reduce the total power provided by the FC, and therefore the consumed hydrogen. To do this, a mathematical modeling is developed taking into account the satisfaction of the power demand on DC-bus while respecting the different constraints of system functioning and source design. The non-linear modeling developed to minimize the hydrogen consumption contains the following decision variables:

$P_{f c}(t)$ : Power supplied by the FC at time $t$,

$V_{f c}(t)$ : FC voltage at time $t$,

$I_{f c}(t)$ : Current supplied by the FC at time $t$,

$\operatorname{Ibus}(t)$ : Output current of the boost converter at time $t$, 
$I_{B}(t)$ : Current supplied/recovered by the battery at time $t$,

$V_{B}(t)$ : Battery voltage at time $t$,

$\operatorname{SOC}(t)$ : State of charge of the battery at time $t$.

The objective function (7) is used to minimize the energy quantity supplied by the $\mathrm{FC}\left(\mathrm{Pb} 2=\mathrm{H}_{2}\right.$ consumption is minimized) during the overall mission.

$$
\min \sum_{t k=1}^{T} P_{f c}(t k)
$$

And (8) used for the energy losses minimization of the global system (Pb1 global efficiency).

$$
\min \sum_{t k=1}^{T}\left(R_{s}+R_{v}\left(I_{f c}\right)\right) \cdot i_{f c}^{2}+R_{B} \cdot i_{B}^{2}
$$

The constraints of the model are:

- Satisfaction of Power demand when the vehicle is in traction $(\mathrm{P}>0)$ and recovering energy from the load and the FC if necessary, when the vehicle brakes $(\mathrm{P}<0)$ :

$$
\begin{gathered}
I_{\text {bus }}(t)+I_{B}(t)=I_{\text {busload }}(t) \forall t \in T \quad P>0 \\
I_{\text {bus }}(t)+I_{B}(t) \geq I_{\text {busload }}(t) \forall t \in T \quad P<0
\end{gathered}
$$

- The voltage of the FC is calculated using the fixed voltage, static and variable resistors (3).

- The value of the variable resistor is calculated using the FC current and polynomial approximation of degree 15 (4) in order to reduce errors.

- The FC can supply a maximum power of $P^{\max }$ and minimum power of $P^{\min }$ to maintain the proper functioning of its auxiliary: $P_{f c}^{\min } \leq P_{f c} \leq P_{f c}^{\max }$

- The power supplied/recovered by the battery:

- Evolution of the state of charge of the battery

$$
P_{B}(t)=I_{B}(t) V_{B}(t)
$$

$$
\operatorname{SOC}(t)=\operatorname{SOC}(t-1)-\left(\frac{I_{B}(t) \Delta t}{Q_{\max } * 3600}\right) \forall t \in T
$$

- Storage capacity of the battery limited to:

$S O C^{\min } \leq \operatorname{SOC}(t) \leq S O C^{\max }$

- The battery voltage expressed in (2).

By summarizing all the equations, the following global model $(\mathrm{Pb} 2)$ is obtained:

$$
\begin{gathered}
\min \sum_{t k=1}^{T} P_{f c}(t k) \\
I_{b u s}(t)+I_{B}(t)=I_{\text {busload }}(t) \text { if Pbusload }>0 \\
I_{b u s}(t)+I_{B}(t) \geq I_{\text {busload }}(t) \text { if Pbusload }<0 \\
P_{f c}(t)=E_{\text {oc }}-R_{S} i_{f c}-\sum_{i=0}^{n} a_{i} \cdot i_{f c}{ }^{n-i} \cdot i_{f c} \\
\text { s.t. } P_{f c}^{\min } \leq P_{f c} \leq P_{f c}^{\max }(t) V_{f c}(t) \\
P_{b u s}(t)=P_{f c}(t) \mathrm{n}=I_{b u s}(t) V_{B}(t) \\
P_{B}(t)=I_{B}(t) V_{B}(t) \\
\operatorname{SOC}(t)=S O C(t-1)-\left(\frac{I_{B}(t) \Delta t}{Q_{\max } * 3600}\right) \forall t \in T
\end{gathered}
$$

s.t. $\quad S O C^{\min } \leq \operatorname{SOC}(t) \leq \operatorname{SOC}^{\max }$ 


$$
\begin{gathered}
\text { Ebat }_{o c v}=\sum_{i=0}^{n} b_{i} . S O C^{n-i} \\
V_{B}=E_{b a t} t_{o c v}-R . I_{b a t}
\end{gathered}
$$

Fig 10 presents a blockset of the problem computation, presenting first the data computation block, feeding the cost evaluation of the objective function, respecting (or not) constraints allowing step by step to search the optimal splitting at each instant $t k$ minimizing the overall objective function.

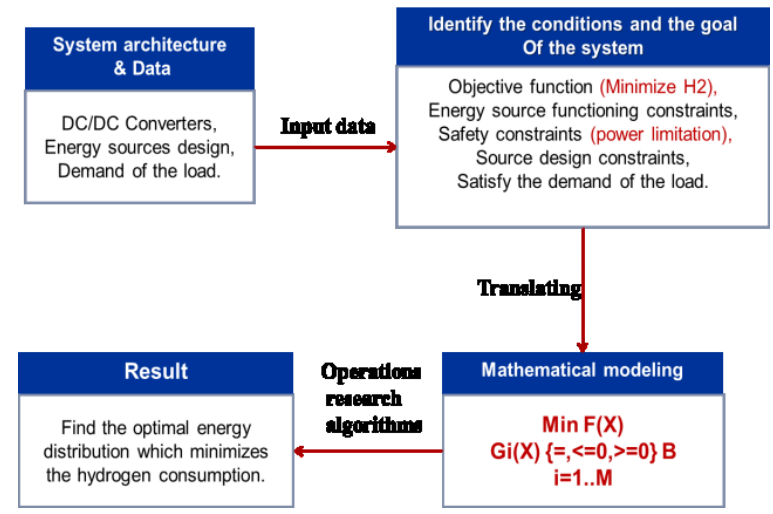

Fig. 10. Global simulation environment

The resolution of the problem is made off-line using a non linear algorithm IPOpt (Interior Point Optimizer) combined with AMPL modeler (Modeling Language for Mathematical Programming) to write the mathematical model in appropriate format. The IPOpt algorithm is an open source solver of COIN-OR platform solving a nonlinear problem (NLP) see [15-18], as shows Fig. 11.

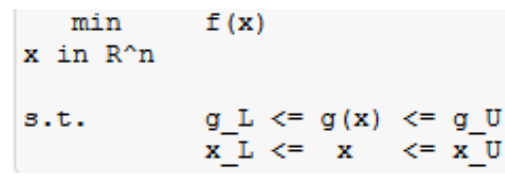

Fig. 11. AMPL example

where $f(x): R^{\wedge} n-->R$ is the objective function, and $g(x): R^{\wedge} n-->R^{\wedge} m$ are the constraint functions. The vectors g_L and g_U denote the lower and upper bounds on the constraints, and the vectors $x \_L$ and $x \_U$ are the bounds on the variables $x$. The functions $f(x)$ and $g(x)$ can be nonlinear and nonconvex, but should be twice continuously differentiable that is insured by the proposed polynomial formulation obtained in previous parts. The functions in this problem are convex so, the optimality of the solution found is granted.

\section{SIMULATION RESULTS}

Once the power management optimization is applied, the set of voltage and current signals within the propulsion system is obtained, therefore the current reference to be applied in the converter control loop, $\mathrm{i}_{\text {ref }}$ (Fig. 12) is fixed.

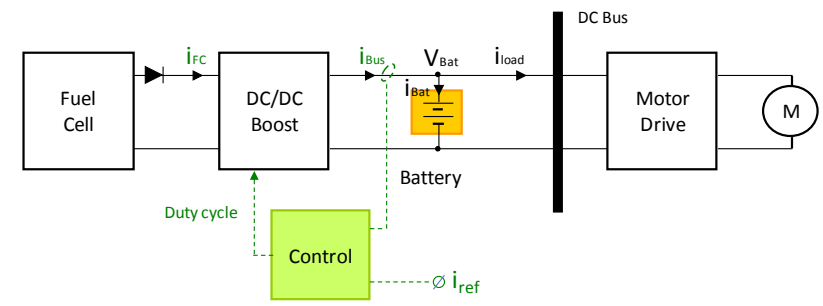

Fig. 12. Current control loop implemented in the powertrain

First of all, the current reference signal obtained by means of both approaches $(\mathrm{Pb} 1$ or $\mathrm{Pb} 2)$ are compared (see Fig. 13), and it can be observed that the obtained result from both objective functions is exactly the same mainly due to the fuel cell losses (due to FC current) which is of paramount importance in this hybrid system. Therefore, henceforth only the fuel cell power minimization data will be used. 




Fig. 13. Current reference signal obtained from fuel cell power minimization and from energy losses minimization, along one ECE15 driving cycle

In order to verify that the developed mathematical model used in the power management optimization is well done, the current reference signal obtained in the power management algorithm is applied to the boost converter control loop. Then, the main current and voltage waveforms evolutions from the mathematical optimization and from the electric simulation are compared, Fig. 14.

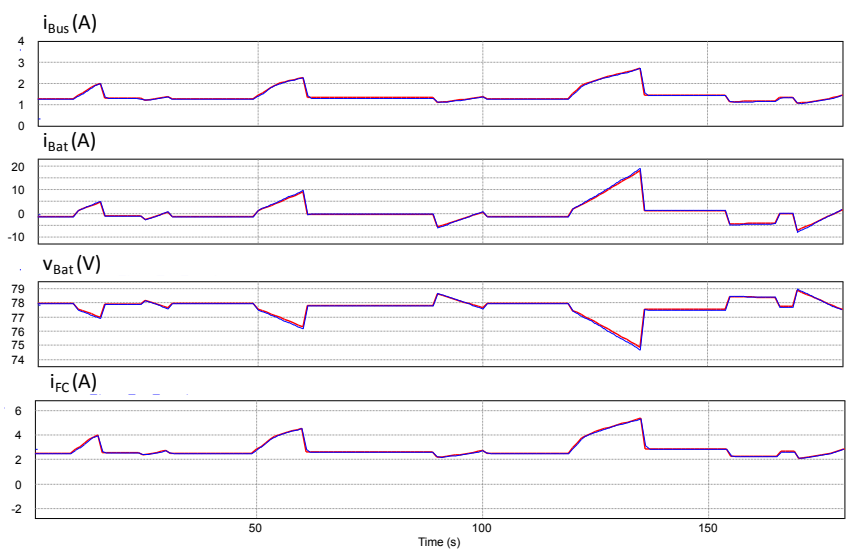

Fig. 14. Mathematical optimization and electric simulation of the powertrain behavior comparison along one ECE15 driving cycle

It can be observed that the signals evolution of both the mathematical modeling and the electrical simulation is the same. Then, it can be conclude that the mathematical algorithm has been properly developed.

Once validated the mathematical formulation, next step consist on comparing the fuel cell hydrogen consumption when the power management (PM) algorithm is applied or not. To do so, the powertrain is simulated in PSIM, and the delivered power by FC is compared when the current reference signal is directly the load demanded current $i_{\text {busload, }}$, or when the current reference signal is the obtained current by means of the optimization algorithm. Fig. 15 shows the fuel cell delivered power with and without power management techniques.

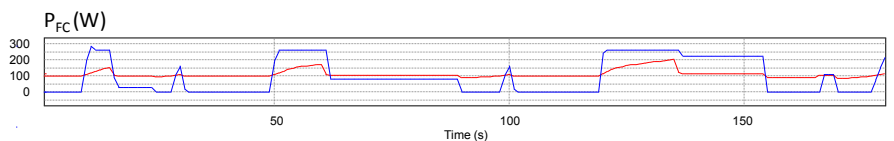

Fig. 15. Fuel cell delivered power with and without power management technique.

The initial battery state of charge is $75 \%$, and by means of the power management optimization algorithm, the final state of charge is around $10 \%$. When the power management is not applied, the battery is discharged along the working day, and when its state of charge is lower than $10 \%$ automatically a recharge procedure is applied, until the state of charge reaches the $75 \%$.

Table II shows the FC energy delivered, with and without power management techniques. It is concluded that within a working day, the difference in the hydrogen consumption is a $24 \%$ gain.

Table II. Results applying or not power management along a working day

\begin{tabular}{|c|c|c|}
\hline & Applying PM & Without PM \\
\hline FC delivered energy (Wh) & 967 & 1200 \\
\hline
\end{tabular}




\section{CONCLUSIONS}

This paper presents a work made in collaboration between two research teams. One based in Spain working on energy sources modeling and the other one based in France focusing their research on energy management optimization method. The discrete time offline optimization is linked in this paper to an accurate and experimental-based sampled non-linear behavior of energy sources. Results obtained on actual data mission profiles allow concluding the method developed is correct, accurate and the optimal results is granted due to the effectiveness of the losses 'dynamically' computed.

The objective functions used to minimize both the total energy losses in the system and the total power delivered by the fuel cell are described. The use of these functions require adequate fuel cell and battery models with the aim of computing both sources behavior, assuring the same operation than the actual FCV under consideration. Then, the optimal power splitting between both sources is achieved, and the global minimum losses in the overall system mission are reached. An important gain in terms of hydrogen energy consumed on the overall mission is obtained increasing the FCV autonomy.

On-board optimization linked to traffic information can be easy to implement and mission profile updated in a given timewindow can replace input data ECE-15. Photovoltaic Panels and/or Supercaps models can also be used in this energy management algorithm. On-line optimization algorithm using these sources model and this mathematical form, also can be now prospected, to be more robust without being too heavy in computation time, allowing to optimally react on disturbances present on an actual driving cycle or uncertainty on sources behavior (default, ageing etc.).

\section{REFERENCES}

[1] Chan, C. C. 2007. "The State of the Art of Electric, Hybrid, and Fuel Cell Vehicles.” Proc. IEEE, 95(4): 704-718, April 2007.

[2] Chau, K., Y. Wong and C. Chan. 1999. "An overview of energy sources for electric vehicles.” Energy Conversion and Management, 40(10):1021-1039.

[3] Brahma, A., Y. Guezennec and G. Rizzoni. 2000. "Optimal energy management in series hybrid electric vehicles." IEEE Proceedings of the American Control Conference, 1(6): 60-64.

[4] Guemri, M., S. Caux and S. U. Ngueveu. 2012. "Using quasi-Newton method for energy management in electrical multi source systems." 11th IEEE International Conference on Environment and Electrical Engineering (EEEIC), Venice, Italy, May 2012, pp. $194-199$.

[5] Koot, M., J.T.B.A. Kessels, B. de Jager, W.P.M.H. Heemels, P.P.J. van den Bosch, and M. Steinbuch. 2005. "Energy management strategies for vehicular electric power systems." IEEE Transactions on Vehicular Technology, 54(3): 771-782

[6] Adegnon, K. M., Y. Dub and K. Agbossou. 2009. "Experimental evaluation of PEM fuel cell systems efficiency." IEEE: Canadian Conference on Electrical and Computer Engineering, (CCECE), pp. 716-719.

[7] Raga, C.; Barrado, A.; Lazaro, A.; Miniguano, H.; Zumel, P.; Sanz, M.; "Optimal sizing of propulsion systems applied to fuel cell based vehicles", IEEE Energy Conversion Congress and Exposition, Sept. 2014.

[8] Tremblay, O. ; Dessaint, L.-A. ; Dekkiche, A.-I., "A Generic Battery Model for the Dynamic Simulation of Hybrid Electric Vehicles", IEEE Vehicle Power and Propulsion Conference, VPPC 2007, Pp.: 284- 289

[9] K. P. Adzakpa, K. Agbossou, Y. Dube, M. Dostie, M. Fournier, A. Poulin, "PEM Fuel Cells Modeling and Analysis Through Current and Voltage Transient Behaviors“, IEEE Trans. Energy Conversion, vol. 23, no. 2, pp. 581-591, Jun. 2008

[10] Boscaino, V. ; Capponi, G. ; Livreri, P. ; Marino, F. "Fuel cell modelling for power supply systems design", in Proc. IEEE Control and Modeling for Power Electronics, 2008, pp. 1-4

[11] Raga, C. ; Barrado, A. ; Lazaro, A. ; Quesada, I. ; Lopez del Moral, D. ; Valdivia, V. "Black-box model and identification methodology for PEM fuel cell with overdamped transient response", IEEE Energy Conversion Congress and Exposition, Publication Year: 2012 , P.: 1176 $-1181$

[12] Raga, C. ; Barrado, A. ; Lazaro, A. ; Fernandez, C. ; Valdivia, V. ; Quesada, I. ; Gauchia, L. "Black-Box Model, Identification Technique and Frequency Analysis for PEM Fuel Cell with Overshooted Transient Response", IEEE Transactions on Power Electronics, Early Access, Publication Year: 2013

[13] Sadoun, R. ; Rizoug, N. ; Bartholomeus, P. ; Barbedette, B. ; Le Moigne, P. "Influence of the drive cycles on the sizing of hybrid storage system battery-supercapacitor supplying an electric vehicle", IEEE Industrial Electronics Society Annual Conference, Publication Year 2011, pp.: 4106-4112

[14] Li Yufang ; Zhou Lili, " Impact of driving cycles and all-electric range on plug-in hybrid vehicle component size and cost", IEEE Vehicle Power and Propulsion Conference, Publication Year: 2009, Pp.: 1708 - 1711

[15] Lougee-Heimer, R. 2003. "The common optimization interface for operations research." IBM Journal of Research and Development, vol. 47, pp. $57-66$

[16] Rardin, R. L. 1998. Optimization in operations research, Prentice-Hall

[17] Winston, W. L. 1994. Operations research: Applications and algorithms, Wadsworth Wachter, A. 2009. "Short tutorial: Getting started with Ipopt in 90 minutes." Combinatorial Scientific Computing, ser. Dagstuhl Seminar Proceedings, Germany 